Research article

\title{
Calcium and methyl jasmonate cross-talk in the secondary metabolism of grape cells
}

\author{
Viviana Martins ${ }^{\mathrm{a}, \mathrm{b}, *}$, Marianne Unlubayir ${ }^{\mathrm{c}}$, António Teixeira ${ }^{\mathrm{a}}$, Hernâni Gerós ${ }^{\mathrm{a}, \mathrm{b}, \mathrm{d}}$, \\ Arnaud Lanoue ${ }^{c}$ \\ ${ }^{a}$ Centre of Molecular and Environmental Biology, Department of Biology, University of Minho, Campus de Gualtar, 4710-057, Braga, Portugal \\ ${ }^{\mathrm{b}}$ Centre for the Research and Technology of Agro-Environmental and Biological Sciences, University of Trás-os-Montes and Alto Douro, 5001-801, Vila Real, Portugal \\ ${ }^{\mathrm{c}}$ Université de Tours, EA 2106 «Biomolécules et Biotechnologie Végétales», UFR des Sciences Pharmaceutiques, 31 Av. Monge, F37200, Tours, France \\ ${ }^{\mathrm{d}}$ Centre of Biological Engineering (CEB), Department of Biological Engineering, University of Minho, Campus de Gualtar, 4710-057, Braga, Portugal
}

\section{A R T I C L E I N F O}

\section{Keywords:}

Calcium-jasmonate signaling

Flavonoids

JAR1

Resveratrol

Transcript-metabolite correlations

Vitis vinifera

Secondary metabolism

STS

\begin{abstract}
A B S T R A C T
In grape cell cultures $c v$. Gamay Fréaux var. Teinturier, Ca was shown to decrease cell pigmentation through the inhibition of anthocyanin biosynthesis, while stimulating stilbenoids accumulation. Because methyl jasmonate (MeJA) is a well-known inducer of secondary metabolism in grape cells, and Ca antagonizes its stimulatory effect over several enzymes of core metabolic branches, in the present study we hypothesized that Ca and MeJA signaling pathways interact to regulate specific secondary metabolism routes. Grape cultured cells were elicited with MeJA or with MeJA + Ca and an UPLC-MS-based targeted metabolomic method was implemented to characterize their polyphenolic profiles. Results were compared with the profile of cells elicited with Ca only, previously reported. Data was complemented with gene expression analysis, allowing the assembly of a metabolic map that unraveled routes specifically regulated by both elicitors. MeJA + Ca specifically boosted Eresveratrol and $E$ - $\varepsilon$-viniferin levels by $180 \%$ and $140 \%$, respectively, in comparison to cells treated with MeJA only, while the stimulatory effect of MeJA over flavonoid synthesis was inhibited by $\mathrm{Ca}$. In parallel, Ca downregulated most flavonoid pathway genes, including LAR1, ANS, BAN and ANR. Ca was able to mimic or potentiate the effect of MeJA on the expression of JA signaling genes, including JAR1, PIN and PR10. Transcript/ metabolite correlation networks exposed the central influence of FLS1, STS, CDPK17 and COI1 in polyphenolic biosynthetic routes. This study highlights the potential of the MeJA-Ca combination for diverting polyphenolic metabolism towards the production of specific metabolites of interest, highly relevant in a biotechnological perspective.
\end{abstract}

\section{Introduction}

Calcium (Ca) has long been recognized as the key intracellular secondary messenger, regulating trans-tonoplast transport of inorganic and organic anions, cell division and turgor, and stability of the cell wall and membranes. Thus, it participates in several essential processes such as growth and differentiation, stomatal opening, pathogen defense, plant-microbe symbioses, and stress adaptation (Hocking et al., 2016; Demidchik et al., 2018). In the grape berry cell wall, exogenous Ca was shown to promote the accumulation of pectin and the inhibition of polygalacturonase enzymes, leading to increased fruit firmness, lower cracking incidence and decreased fungi penetration in the skin, minimizing fruit decay (Martins et al., 2018, 2020b, 2021). The beneficial effects of $\mathrm{Ca}$, particularly $\mathrm{CaCl}_{2}$, over fruit firmness were also assessed in other fruits, including sweet cherry, papaya, apple, strawberry and kiwi (Siddiqui and Bangerth, 1995; Wójcik and Lewandowski, 2003; Antunes et al., 2004; Bonomelli and Ruiz, 2010; Wójcik and Borowik, 2013; Madani et al., 2016). However, the documented effects of Ca in grape berry physiology go beyond the mechanical modifications observed in the fruit skin, given its central role as secondary messenger. Modifications in berry ${ }^{\circ} \mathrm{Brix}$ and titratable acidity upon Ca treatment were reported (Al-Qurashi and Awad, 2013; Ciccarese et al., 2013). Recent studies also showed that $\mathrm{CaCl}_{2}$ sprays around veraison stage increased

* Corresponding author. Centre of Molecular and Environmental Biology, Department of Biology, University of Minho, Campus de Gualtar, 4710-057, Braga, Portugal.

E-mail addresses: vmartins@bio.uminho.pt (V. Martins), marianne.unlubayir@univ-tours.fr (M. Unlubayir), antonio.teixeira@bio.uminho.pt (A. Teixeira), geros@ bio.uminho.pt (H. Gerós), arnaud.lanoue@univ-tours.fr (A. Lanoue). 


\begin{tabular}{|llll|}
\hline \multicolumn{2}{|l|}{ Abbreviations } & JA & jasmonate \\
\multicolumn{2}{|l}{ ACT actin } & JAR & jasmonate-resistant \\
ANR, BAN anthocyanidin reductases & LAC & laccase \\
ANS anthocyanidin synthase & LAR & leucoanthocyanidin reductase \\
CDPK & calcium-dependent protein kinase & LOXO & 13-lipoxygenase \\
COI & F-box protein coronatine insensitive & MeJA & methyl jasmonate \\
CHI & chalcone isomerase & PAL & phenylalanine ammonia lyase \\
CHIT4c & acidic class IV chitinase & PIN & serine protease inhibitor \\
CHS & chalcone synthase & PR & pathogenesis-related protein \\
DFR & dihydroflavonol reductase & STS & stilbene synthase \\
F3' $5^{\prime} \mathrm{H}$ & flavonoid $3^{\prime}, 5^{\prime}$-hydroxylase & UFGT - UDP-glucose flavonoid-3-O-glucosyltransferase \\
F3H & flavanone 3-hydroxylase & UPLC-MS Ultra-performance liquid chromatography coupled to \\
FLS & flavonol synthase & & mass spectrometry \\
& & & \\
\hline
\end{tabular}

total anthocyanin content, estimated by spectrophotometric methods, in grape berries cv. Manicure Finger (Yu et al., 2020). In contrast, targeted metabolomic approaches showed a general repression in the synthesis of several anthocyanins in the grape berry, among which malvidin-3-O-glucoside, in vineyards $c v$. Vinhão sprayed with $\mathrm{CaCl}_{2}$ throughout the fruiting season (Martins et al., 2020a). This effect was also consistently observed in grape cell cultures $c v$. Gamay Fréaux var. Teinturier, which became significantly less pigmented upon Ca treatment, due to a general repression of the entire flavonoid pathway (Martins et al., 2018; Martins et al., 2020a). These studies confirmed the reliability of the above-mentioned cell line to investigate the influence of $\mathrm{Ca}$ in polyphenolic metabolism, through the advantageous fine-tuned control of all experimental conditions, while ruling-out the influence of external factors such as environmental cues which significantly affect the secondary metabolism of the fruits (Teixeira et al., 2013).

Plant hormones like ABA and jasmonates are known to induce secondary metabolism pathways in grape cells and in grape berries (D’Onofrio et al., 2009; Gagné et al., 2011; Ju et al., 2016). Particularly methyl jasmonate (MeJA) has been described as exogenous elicitor of plant defense compounds, among which polyphenols, promoting the synthesis of anthocyanins, flavonols, proanthocyanidins and stilbenes (Larronde et al., 2003; Ruiz-Garcia et al., 2012; García-Pastor et al., 2019). In grape cell cultures $c v$. Gamay Fréaux var. Teinturier, Ca was shown to antagonize the stimulatory effect of MeJA over several enzymes of core metabolic branches, both at protein activity and gene expression levels (Martins et al., 2018). For instance, phenylalanine ammonia lyase (PAL) enzyme was stimulated in cells treated either with $\mathrm{Ca}$ or MeJA, but not in the presence of both. This antagonistic effect was also observed for genes of the stilbenoid and flavonoid pathways, namely STS, DFR and UFGT (Martins et al., 2018).

In the present study we explored in more detail the cross talk between $\mathrm{Ca}$ and MeJA in stimulating or repressing specific secondary metabolic routes in grape cells $c v$. Gamay Fréaux var. Teinturier, through a metabolomic approach combined with expression analysis of key genes of the flavonoid pathway. Results were compared with the metabolic data of cells elicited with Ca only, addressed in our previous study (Martins et al., 2020a). A metabolic map was assembled highlighting the routes specifically regulated by the combination of MeJA and Ca. Correlation networks of transcripts and metabolites exposed specific links in JA signaling and secondary metabolism pathways.

\section{Material and Methods}

\subsection{Grape cell culture conditions}

Pigmented cells of $V$. vinifera L. $c v$. Gamay Fréaux var. Teinturier, gently provided by Prof. Serge Delrot (University of Bordeaux, France), were subcultured weekly in liquid Gamborg B5 medium including vitamins supplemented with $2 \%$ sucrose, and cultivated under an $8 \mathrm{~h}$ dark/16 h light $\left(200 \mu \mathrm{mol}\right.$ photons $\left.\mathrm{m}^{-2} \mathrm{~s}^{-1}\right)$ photoperiod, at $24{ }^{\circ} \mathrm{C}$ (Decendit and Mérillon, 1996; Martins et al., 2018, 2020a). $\mathrm{CaCl}_{2}$ and MeJA were added to the cultures at day 3 to achieve final concentrations of $10 \mathrm{mM}$ and $20 \mu \mathrm{M}$, respectively, as optimized in our previous study (Martins et al., 2018). Elicitors were added to cell cultures separately or combined, and non-treated cells were used as control. Experiments were performed in triplicate. Cells were harvested after $12 \mathrm{~h}$ for analysis of gene expression or after $4 \mathrm{~d}$ for analysis of polyphenolic profile. Filtered cells were frozen in liquid nitrogen, ground to a fine powder and stored at $-80{ }^{\circ} \mathrm{C}$.

\subsection{Characterization of cell metabolic profile}

Metabolites were extracted from $25 \mathrm{mg}$ of lyophilized samples using $1 \mathrm{~mL}$ of $80 \%(\mathrm{v} / \mathrm{v})$ methanol. After $30 \mathrm{~min}$ of sonication, samples were macerated overnight at $4{ }^{\circ} \mathrm{C}$ in the dark and centrifuged at $18,000 \mathrm{~g}$ for $10 \mathrm{~min}$. The supernatant was recovered to new tubes and stored at $-20^{\circ} \mathrm{C}$ prior to further analyses (Billet et al., 2018a, b, c; Martins et al., 2020a). UPLC-MS targeted metabolomic analysis was performed using an ACQUITYTM Ultra Performance Liquid Chromatography system coupled to a photo diode array detector (PDA) and a Xevo TQD mass spectrometer (Waters, Milford, MA) equipped with an electrospray ionization (ESI) source controlled by Masslynx 4.1 software (Waters, Milford, MA). Analyte separation was achieved by using a Waters Acquity HSS T3 C18 column $(150 \times 2.1 \mathrm{~mm}, 1.8 \mu \mathrm{m})$ with a flow rate of 0.4 $\mathrm{mL} \mathrm{min}^{-1}$ at $55{ }^{\circ} \mathrm{C}$. Chromatographic separation and identification of analytes was achieved as described previously (Martins et al., 2020a) (supplementary table S1). Heatmaps were performed in R software version 3.5.3 using the ComplexHeatmap package 1.18.1 on Bioconductor 3.9.

\subsection{RNA extraction and $q P C R$ analysis of genes involved in secondary metabolism and jasmonate response}

Total RNA was extracted from $0.3 \mathrm{~g}$ of ground samples following the classical method described by Reid et al. (2006), and cDNA was synthesized from $1 \mu \mathrm{g}$ purified RNA with Omniscript ${ }^{\circledR}$ RT Kit and oligo (dT) primers (Qiagen), following the manufacturer's instructions. Quantitative real-time PCR (qPCR) reactions were performed in triplicate, as previously optimized (Martins et al., 2018, 2020a, b). The sequences of gene-specific primers used were retrieved from previously published studies, as detailed in supplementary table S2. Genes encoding core enzymes of the flavonoid pathway were selected, namely CHI1 (chalcone isomerase), $F 3^{\prime} 5^{\prime} H$ (flavonoid $3^{\prime}, 5^{\prime}$-hydroxylase), $F 3 H 1$ (flavanone 3-hydroxylase), LAR1 (leucoanthocyanidin reductase), ANS (anthocyanidin synthase), BAN and ANR (anthocyanidin reductases leading to the formation of catechin and epicatechin, respectively) (Jeong et al., 2004; 
Bogs et al., 2005; Castellarin et al., 2007; Tavares et al., 2013). LAC encoding a laccase reportedly involved in $E$-resveratrol oxidation (Tavares et al., 2013) was also selected, together with key genes involved in JA pathway and stress response, namely LOXO (13-lipoxygenase) involved in JA biosynthesis, JAR1 (JA-resistant) and COI1 (F-box protein coronatine insensitive) involved in JA signaling, CDPK17 (Ca-dependent protein kinase 17), PIN (serine protease inhibitor), CHIT4c (acidic class IV chitinase) and PR1O (pathogenesis-related protein 10) involved in responses to stress and pathogen defense (Belhadj et al., 2008; Chen et al., 2013; Figueiredo et al., 2015). The specificity of PCR reactions was checked through dissociation curves at the end of each qPCR reaction, by heating the amplicons from 65 to $95{ }^{\circ} \mathrm{C}$. Gene expression was normalized to GAPDH and ACT1 reference genes (Martins et al., 2020a) using the $\Delta \Delta \mathrm{Cq}$ method in CFX Manager Software 3.1 (Bio-Rad laboratories, Inc.).

\subsection{Network analysis}

A correlation was assembled using MetScape plugin from Cytoscape version 3.8.1 (www.cytoscape.org; Cline et al., 2007), from a matrix of metabolites and transcript values of grape cell cultures treated with MeJA, Ca, and MeJA + Ca normalized to the respective controls (Teixeira et al., 2020). In the network diagram, generated using a perfuse force direct layout algorithm, node size is proportional to the correlation node strength (ns $=|\rho|$ ) and edge (line) thickness is proportional to the Pearson correlation values. Positive $(\rho>0.90)$ and negative $(\rho<-0.90)$ correlations are shown in red and blue, respectively. Different node shapes were used to distinguish genes from metabolites, and colors were used to distinguish metabolic classes and biosynthetic pathways. MCODE plugin was used to obtain a series of metrical topological parameters of the network, allowing, on mathematical basis, to unravel the denser areas and distinguish the subnetworks with strong transcript-metabolite, transcript-transcript and metabolite-metabolite cross-links (Teixeira et al., 2020).

\subsection{General statistical analysis}

The Student's $t$-test and one-way ANOVA were used to statistically analyse the results, in Prism ${ }^{\circledR 6}$ (GraphPad Software, Inc.). In graphs, significant differences are marked by different letters $(a, b, c)$ and in heatmaps are marked with asterisks to denote the significance level of MeJA treatment versus MeJA + Ca: * $P \leq 0.05 ;{ }^{* *}, P \leq 0.01{ }^{* * *}, P \leq$ 0.001 .

\section{Results}

\subsection{Effect of MeJA-Ca interactions on grape cell metabolic profile}

A total of 48 metabolites were detected and identified by UPLC-MS in cultures from grapes of $V$. vinifera L. $c v$. Gamay Fréaux var. Teinturier treated with MeJA, MeJA + Ca and without treatment (control) (supplementary tables S1, S3), including 6 amino acids, 5 phenolic and organic acids, 11 stilbenoids, 5 flavonols, 11 flavan-3-ols and 10 anthocyanins. Unsupervised PCA score plot of the two first components readily discriminated the metabolic profiles of cells subjected to each of the treatment (Fig. 1A). The corresponding loading plot showed metabolites that were responsible for the differences in these profiles (Fig. 1B). In general, the treatments with MeJA and MeJA + Ca caused an evident overaccumulation of metabolites, in comparison to control cells. Stilbenoids DP1 were significantly more abundant in cells treated with $\mathrm{MeJA}+\mathrm{Ca}$, while the remaining metabolic classes were more abundant in cells treated with MeJA only (Fig. 1C). The treatments produced no significant effects in the levels of phenolic and organic acids (supplementary figure S1).

Regarding amino acids, results showed equivalent amounts in control cells and in cells treated with MeJA alone. In turn, L-phenylalanine
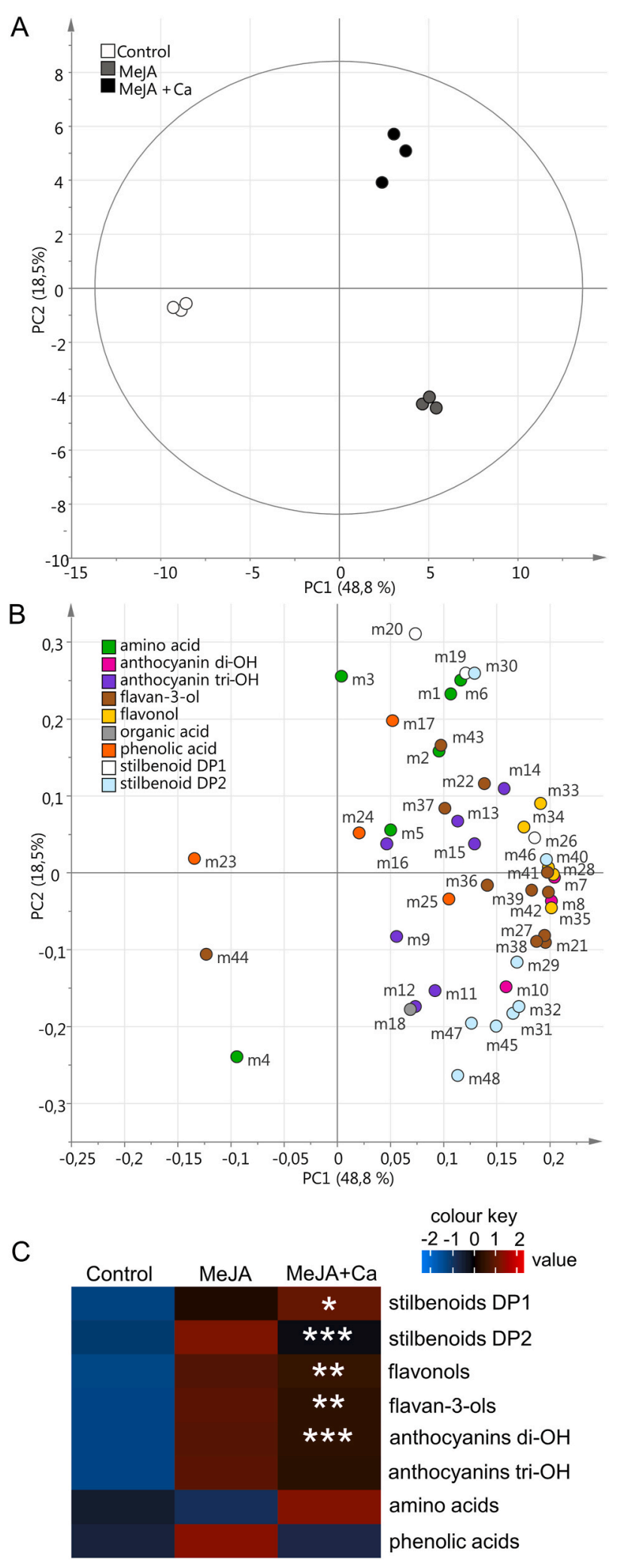

Fig. 1. Unsupervised classification using PCA and heatmap on metabolomic data from grape cells treated with MeJA, MeJA + Ca or without treatment (control). Variables in the score plot (A) were colored according to the treatment and variables in loading plot (B) were colored according to metabolic class. Numbers indicate the ID of metabolites as given in supplementary table S1. Heatmap with the relative abundance of major metabolic classes for each treatment (C); asterisks indicate statistical significance of MeJA vs MeJA + Ca following Student's $t$-test: ${ }^{*} P \leq 0.05 ;{ }^{* *} P \leq 0.01 ; * * * P \leq 0.001$. 
levels were lower in cells treated with MeJA + Ca than in cells treated with MeJA only, while the opposite was observed for L-tryptophan, Lproline and L-isoleucine (Fig. 2).

Regarding stilbenoids, a clear trade-off was observed between the levels of stilbenoids DP1 and DP2 among cells treated with MeJA versus MeJA + Ca, as described above (Fig. 2). Whereas the former mostly accumulated stilbenoids DP2, the later accumulated higher levels of stilbenoids DP1. These included $E$-resveratrol which increased by $180 \%$ in cells treated with MeJA + Ca compared to cells treated with MeJA only. In addition, E-piceatannol was specifically over-accumulated (by 4-fold) in the presence of Ca. All stilbenoids DP2 were increased in cells treated with MeJA in comparison to control cells, but the combination of MeJA + Ca generally inhibited this tendency (Fig. 2). This effect was visible for resveratrol dimers glucosides, pallidol, $E$ - $\delta$-viniferin and $E$ $\omega$-viniferin. The notable exception was for $E$ - $\varepsilon$-viniferin which increased by $140 \%$ in cells treated with MeJA + Ca in comparison to cells treated with MeJA only.

The treatment with MeJA significantly increased the levels of all flavonols, in comparison to control cells, namely kaempferol, quercetin and myricetin conjugates (Fig. 3). In the presence of $\mathrm{MeJa}+\mathrm{Ca}$, a small but significant decrease of $\sim 10 \%$ was observed in the levels of kaempferol glucoside and myricetin-hexoside, while quercetin derivatives

\section{Amino acids}

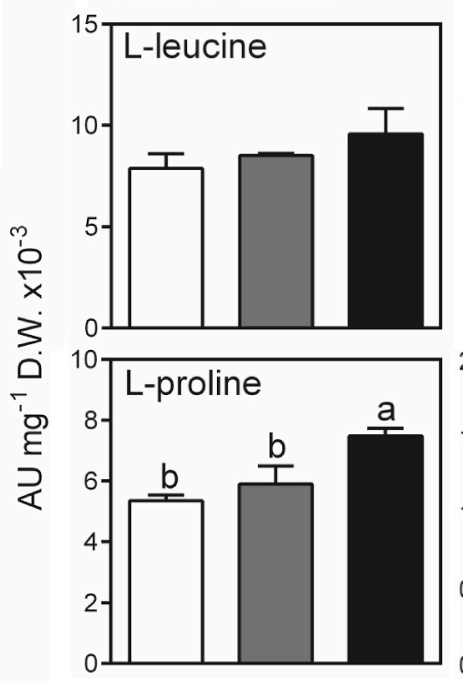

Stilbenoids DP1
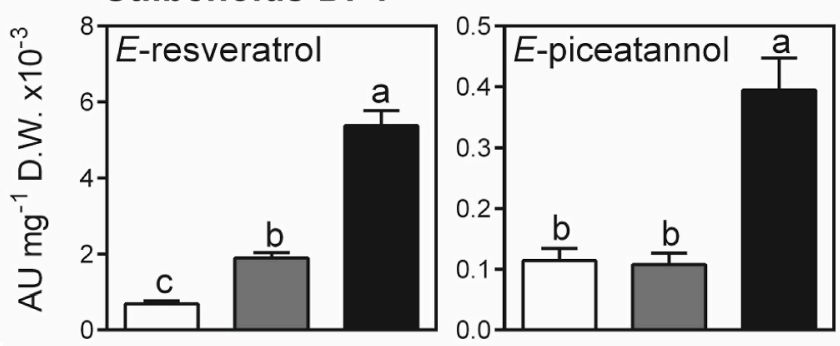

Stilbenoids DP2
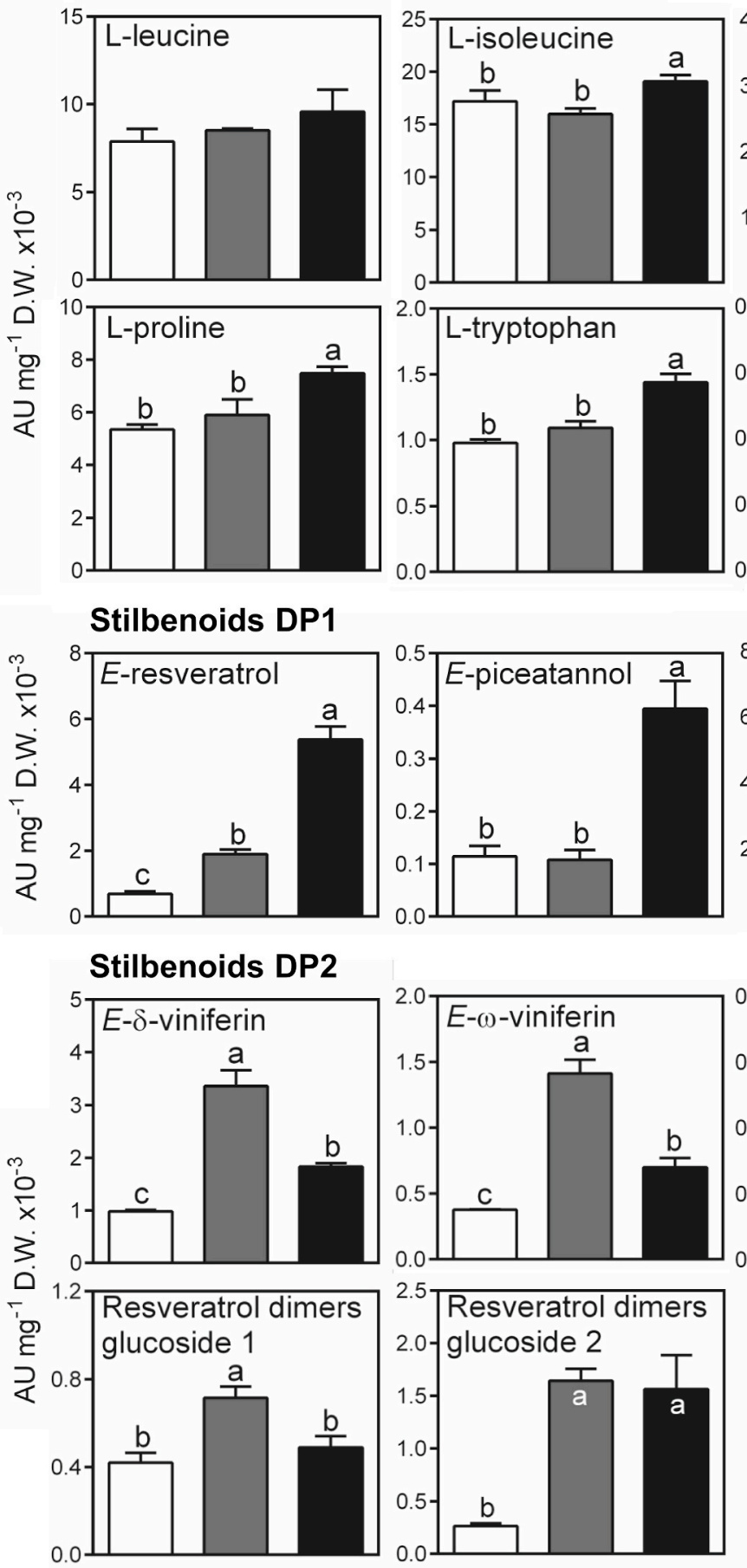
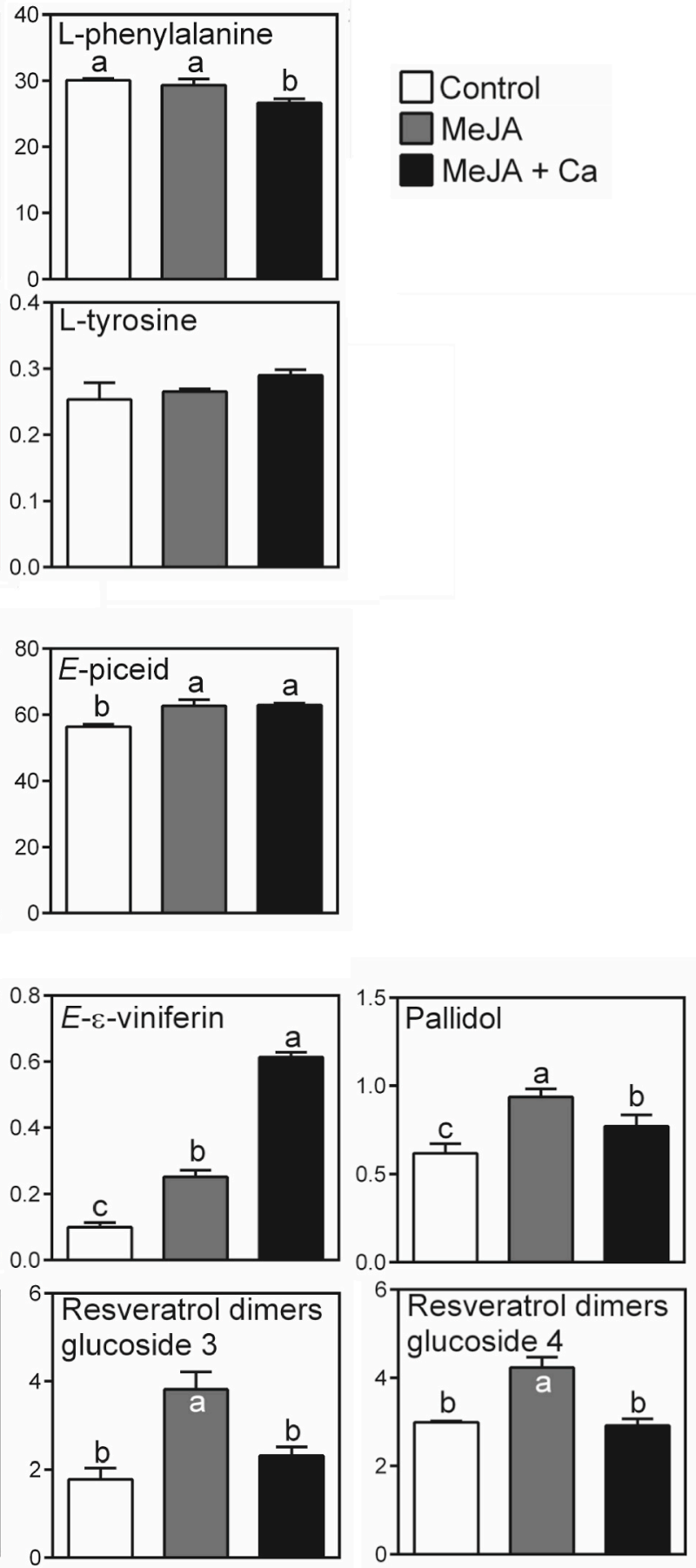

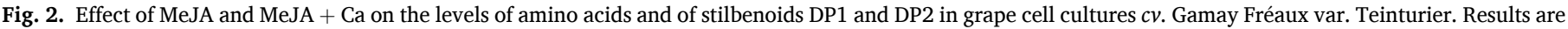
expressed as mean \pm SD and significant differences are indicated by different letters. 

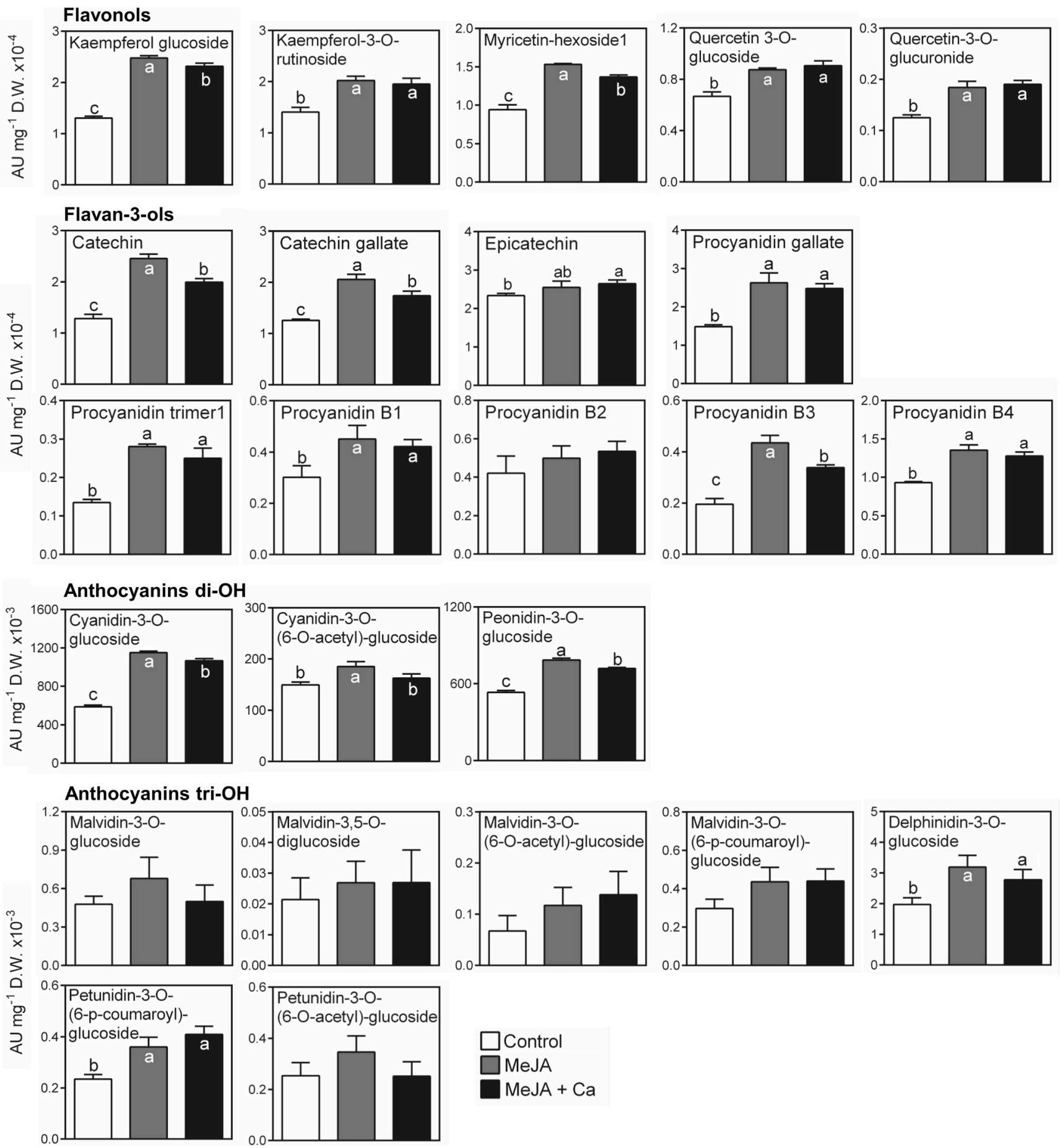

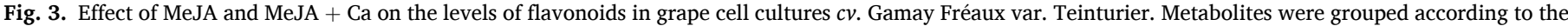

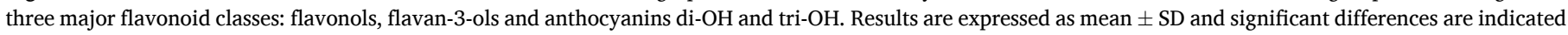
by different letters.

were not affected.

MeJA treatment also stimulated the production of most flavan-3-ols, including catechin, epicatechin and procyanidins. The effect of MeJa + $\mathrm{Ca}$ in these cells was once again restricted to a few metabolites in this class, specifically catechin and catechin gallate which decreased by 15-20\%. A significant decrease was also observed for the levels of procyanidin $\mathrm{B} 3$, unlike that observed for all other procyanidins detected (Fig. 3, supplementary table S3).

Lastly, cells treated with MeJA significantly contained higher levels of anthocyanins di-OH, in comparison to control cells, while for anthocyanins tri-OH this effect was observed for delphinidin and petunidin conjugates, but not for any of the malvidin forms detected (Fig. 3). The combined MeJA + Ca treatment caused an $8-13 \%$ decrease in the levels of all anthocyanins di-OH detected, including both cyanidin and peonidin conjugates, in comparison to cells treated with MeJA only. In contrast, none of the anthocyanins tri-OH was significantly affected.

To investigate the molecular nature of the specific metabolic shifts triggered by $\mathrm{Ca}$ in MeJA-treated cells, the expression of genes encoding key enzymes involved in the biosynthesis of polyphenols was investigated. While in a previous study we focused on genes involved in the 
major metabolic branches (PAL1, STS, CHS3, FLS1, DFR and UFGT; Martins et al., 2018), in the present study we selected genes involved in inner ramifications of the flavonoid pathway, together with a polyphenol oxidase/laccase-encoding gene (see Material and Methods for details). As shown in Fig. 4A, transcript levels of CHI1 encoding chalcone isomerase increased by $37 \%$ upon MeJA treatment, in comparison to control, while the treatment with $\mathrm{Ca}$ alone or MeJA + Ca produced no significant effects. Both $F 3^{\prime}, 5^{\prime} H$ and $F 3 H 1$ encoding flavonoid $3^{\prime}, 5^{\prime}$-hydroxylase and flavanone 3-hydroxylase, respectively, were downregulated in cells treated with $\mathrm{Ca}$ or MeJA alone (by 33-60\%), in comparison to control cells. The combination MeJA + Ca further accentuated this effect by up to $90 \%$. Transcript levels of $L A R 1$ encoding leucoanthocyanidin reductase were upregulated by MeJA, and the combination of MeJA + Ca resulted in a sharp downregulation of gene expression $(>50 \%)$ to levels below those detected in control cells or cells treated with Ca only which produced no changes in gene expression. This trend was also observed for the expression of BAN and ANR encoding anthocyanidin reductases. Transcript levels of ANS encoding anthocyanidin synthase were also lower in cells treated with MeJA + Ca than in cells treated with MeJA only. Lastly, transcript levels of $L A C$ encoding a laccase reportedly involved in $E$-resveratrol oxidation were
$80 \%$ lower in cells treated with MeJA + Ca or Ca only than in control cells (Fig. 4A). The treatment with only MeJA produced no significant changes in the expression of this gene.

\subsection{Effect of MeJA and Ca on the expression of genes involved in jasmonate synthesis, signaling and stress response}

To further understand the nature of the interaction between $\mathrm{Ca}$ and MeJA, the effect of the treatments on the expression of genes involved in JA biosynthesis, signaling and stress response was investigated (Fig. 4B). Transcript levels of LOXO encoding a lipoxygenase involved in JA biosynthesis were upregulated by $37 \%$ in response to MeJA treatment, and this effect was accentuated by $150 \%$ by the combination of MeJA + $\mathrm{Ca}$. The treatment with $\mathrm{Ca}$ alone produced no effects on $L O X O$ expression. The expression of JAR1 involved in JA signaling was upregulated by the treatments with $\mathrm{Ca}$ or MeJA alone, and their combination accentuated this effect by up to $80 \%$. In turn, transcript levels of COI1 acting downstream of $J A R 1$, were specifically upregulated in cells treated with Ca alone, while none of the other treatments produced significant effects. The expression of CDPK17 encoding a Ca-dependent protein kinase highly responsive to abiotic stress were upregulated by

A
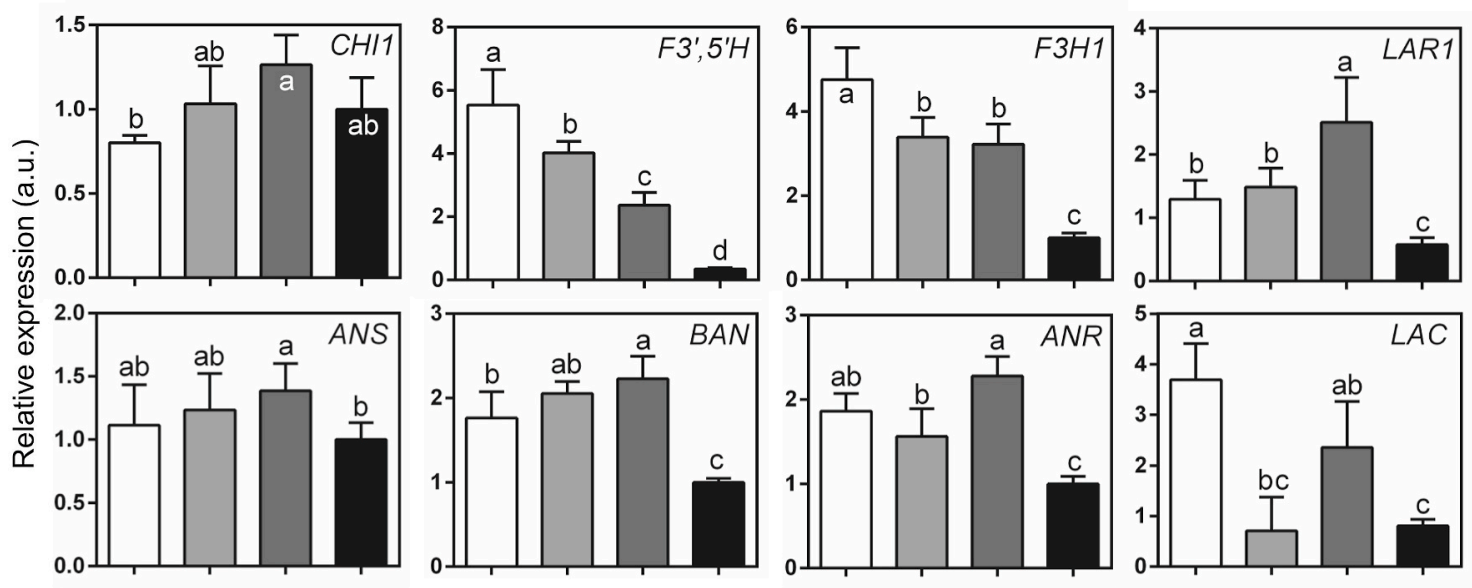

B
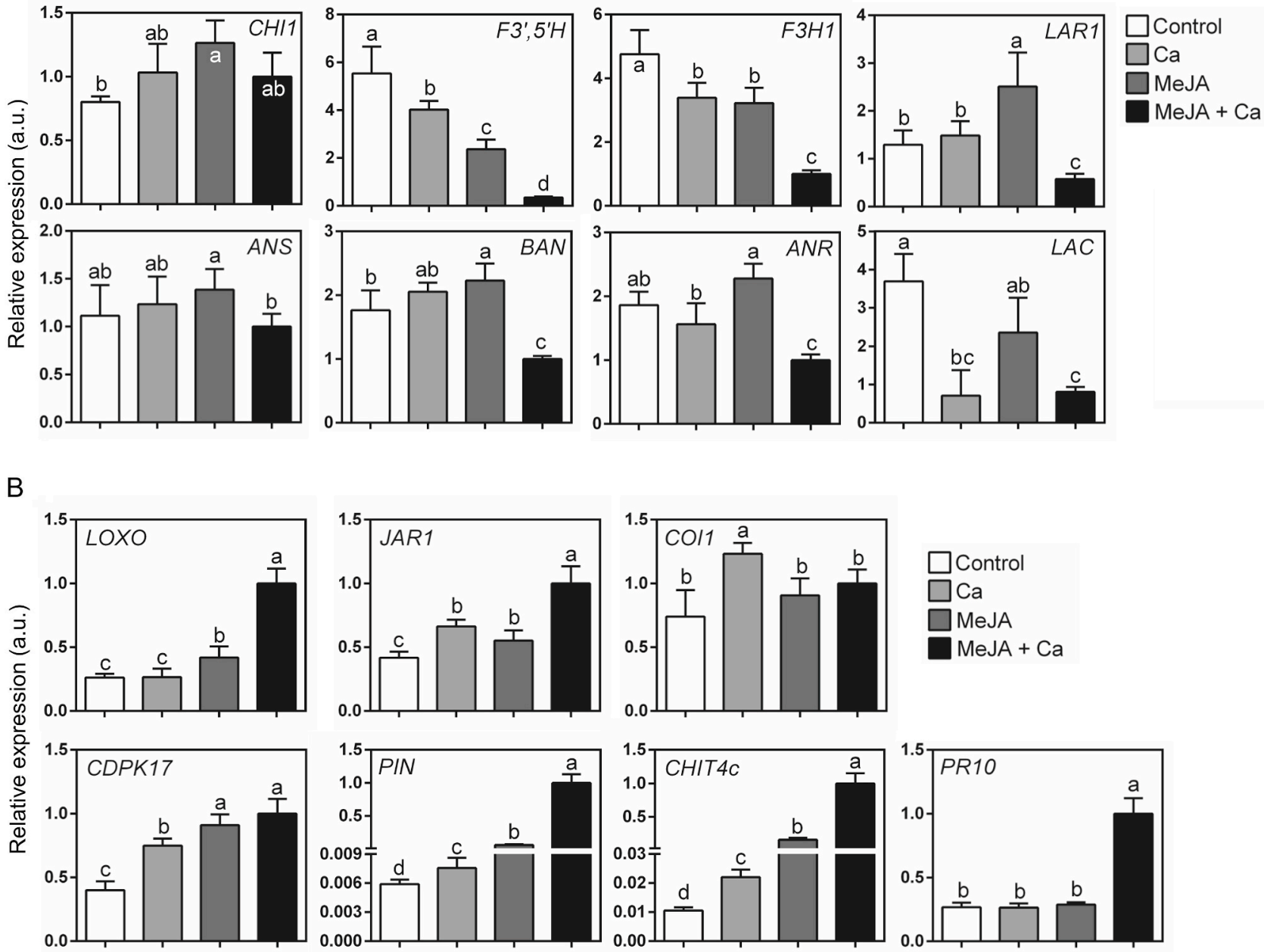

Fig. 4. Effect of MeJA, MeJA + Ca and Ca on the expression of core genes of the flavonoid pathway and polyphenol oxidase (A) and of genes of the jasmonate pathway and stress response (B) in grape cell cultures $c v$. Gamay Fréaux var. Teinturier. Transcript levels are shown for chalcone isomerase (CHI1), flavonoid $3^{\prime}, 5^{\prime}$ hydroxylase $\left(F 3^{\prime}, 5^{\prime} H\right)$, flavanone 3-hydroxylase $(F 3 H 1)$, leucoanthocyanidin reductase (LAR1), anthocyanidin synthase (ANS), anthocyanidin reductases $(B A N, A N R)$, polyphenol oxidase/laccase ( $L A C$ ), 13-lipoxygenase (LOXO), JA-resistant (JAR1), F-box protein coronatine insensitive (COI1), Ca-dependent protein kinase 17 (CDPK17), serine protease inhibitor (PIN), acidic class IV chitinase (CHIT4c) and pathogenesis-related protein 10 (PR10). Expression levels were normalized to the transcript levels of GAPDH and ACT1 (housekeeping genes). Results are expressed as mean $\pm \mathrm{SD}$ and significant differences are indicated by different letters. 
$90 \%$ in cells treated with Ca alone, and by up to $150 \%$ in cells treated with MeJA either applied alone or in combination with $\mathrm{Ca}$. The genes involved in pathogen response PIN and CHIT4c were upregulated by $25-100 \%$ in cells treated with Ca only, and by $1000-1500 \%$ in cells treated with MeJA only, and the combination MeJA + Ca accentuated this effect by up to 125-fold, demonstrating a strong synergistic effect between $\mathrm{Ca}$ and MeJA. The expression of PR10 was specifically stimulated by the combination of MeJA $+\mathrm{Ca}$, remaining unaffected by all other treatments (Fig. 4B).

\subsection{Separate and joint effects of Ca and MeJA on polyphenolic metabolism and JA pathway genes}

A combination of the results obtained in the present study and in previous studies (Martins et al., 2018, 2020a, 2020a), where the isolated effect of Ca on secondary metabolism was investigated, allowed the assembly of a metabolic map of the effects of Ca, MeJA and MeJA + Ca in grape cells, showing the influence of each treatment at both metabolite and transcript levels (Fig. 5). In the stilbenoid pathway, the upregulation of STS-encoding genes and inhibition of LAC were accompanied by a generalized overaccumulation of stilbenoids DP1 and DP2. While $\mathrm{Ca}$ and MeJA led to increased stilbenoid levels when applied alone, their combination specifically potentiated the accumulation of $E$-resveratrol and $E$ - $\varepsilon$-viniferin, showing a directed synergistic action of the elicitors, which was not observed for the remaining stilbenoids. For instance, for $E$-piceatannol and E-piceid only Ca or MeJA were responsible for their overaccumulation, respectively. It was also observed that although $\mathrm{Ca}$ or MeJA treatments increased the levels of $E$-resveratrol and resveratrol dimers, their combination clearly favored the accumulation of the former in detriment of the later. A clear trade-off was also observed
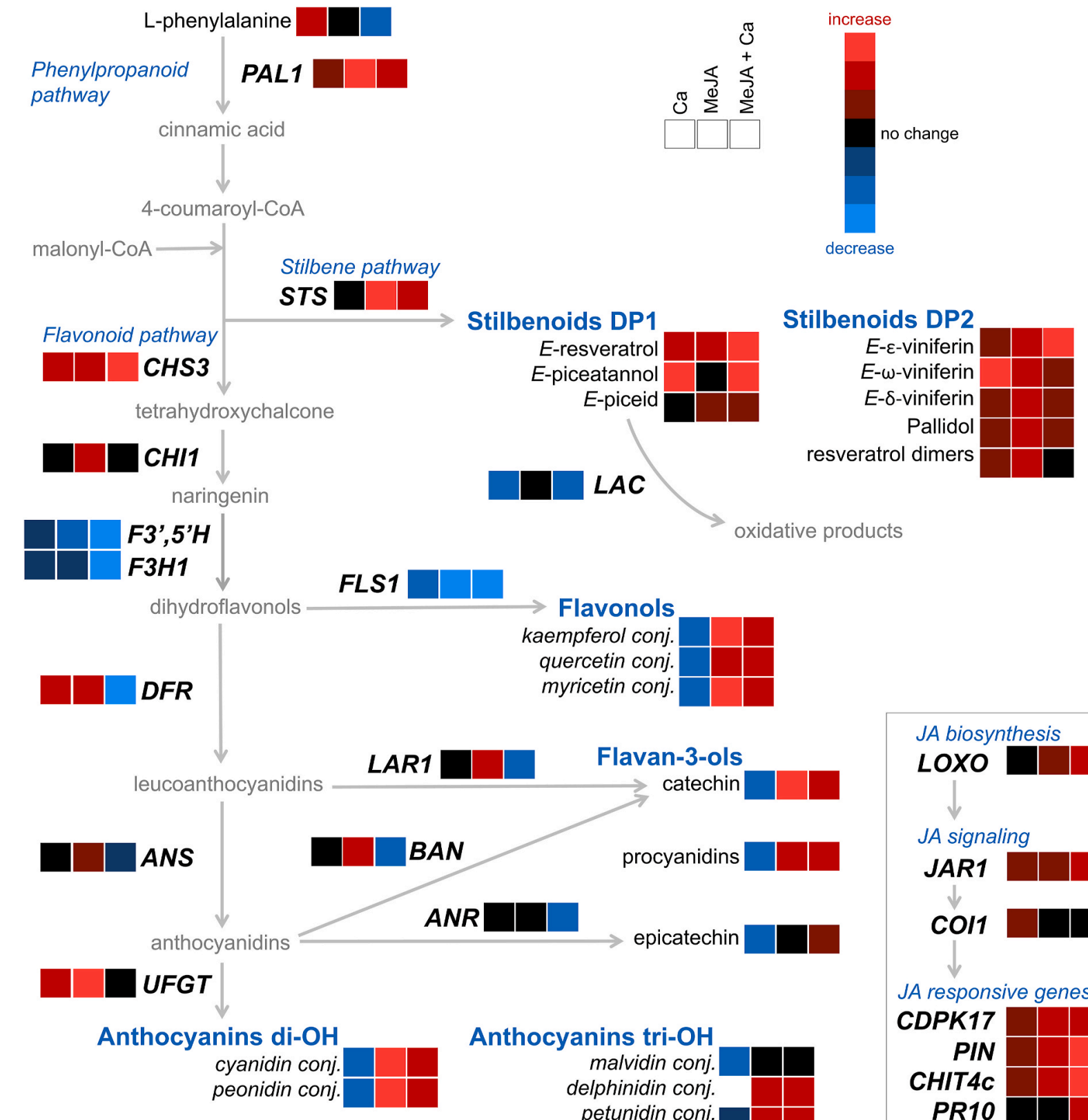
between $E$ - $\varepsilon$-viniferin and the other two viniferins detected, $E$ - $\delta$-viniferin and $E$ - $\omega$-viniferin.

The synergistic effect of MeJA + Ca also included the early stages of the flavonoid pathway, namely the expression of $C H S 3, F 3^{\prime}, 5^{\prime} H, F 3 H 1$ and FLS1. In contrast, visible antagonistic effects of the MeJA + Ca combination were observed for all genes leading to flavan-3-ol and anthocyanin biosynthesis, namely DFR, LAR1, ANS, BAN, ANR and $U F G T$, most genes being stimulated by MeJA and/or Ca alone but inhibited in the presence of both. At metabolite level, it was observed that the accumulation of flavonols, catechin and anthocyanins di-OH was inhibited by $\mathrm{Ca}$ and generally stimulated by MeJA, and the combination of the treatments resulted in a lower-degree accumulation of metabolites, reflecting a sum of the effects observed with the isolated treatments (Fig. 5).

In parallel, a cumulative synergistic effect of $\mathrm{Ca}$ and MeJA was observed in the expression of LOXO, JAR1, PIN and CHIT4c, while PR1O was solely overexpressed in the presence of both elicitors.

\subsection{Correlation networks of transcripts and metabolites}

The relationships between transcripts and metabolites in cells elicited with Ca and/or MeJA were explored through a correlation network using a matrix of Pearson correlation coefficient values ( $\rho$ ) (supplementary table S4). The overall network strength was high $(|\rho|=0.68$;
Evans et al., 1996), translating high transcript-metabolite, transcript-transcript and metabolite-metabolite correlations (Fig. 6, supplementary table S4). Node strength (ns) calculation, intended as the average of all the $|\rho s|$ yielded by each node, was used to identify the main elements ("hubs") of the network (supplementary table S4). In the network diagram, four main clusters could be distinguished (Fig. 6, supplementary figure S2), the largest one (ns $\geq 0.69$ ) comprising FLS1, CDPK17 and COI1 grouped to 29 metabolites which include all classes of flavonoids, E-piceid, caftaric and coutaric acids, L-phenylalanine, L-tryptophan and resveratrol dimers glucoside 2. FLS1 is located in the center of this cluster, establishing negative correlations with CDPK17 and with all metabolites, with the exception of $E$-piceid, L-phenylalanine and coutaric acid. In turn, these metabolites and also L-tryptophan negatively correlate with most metabolites and transcripts in this cluster. This pattern is not observed for other metabolites, which mostly establish positive metabolite-metabolite correlations. CDPK17 and COI1 locate in opposite sides of the cluster, the former positively correlating with 25 metabolites, and the latter negatively correlating with 30 metabolites. STS is located at the periphery of this cluster, negatively correlating with COI1 and establishing positive correlations with most metabolites, in a pattern opposite to that of FLS1 (Fig. 6).

The remaining three clusters comprised only 12 metabolites (stilbenoids and amino acids) and 17 transcripts (Fig. 6). The second largest cluster includes the remaining transcripts of JA signaling together with

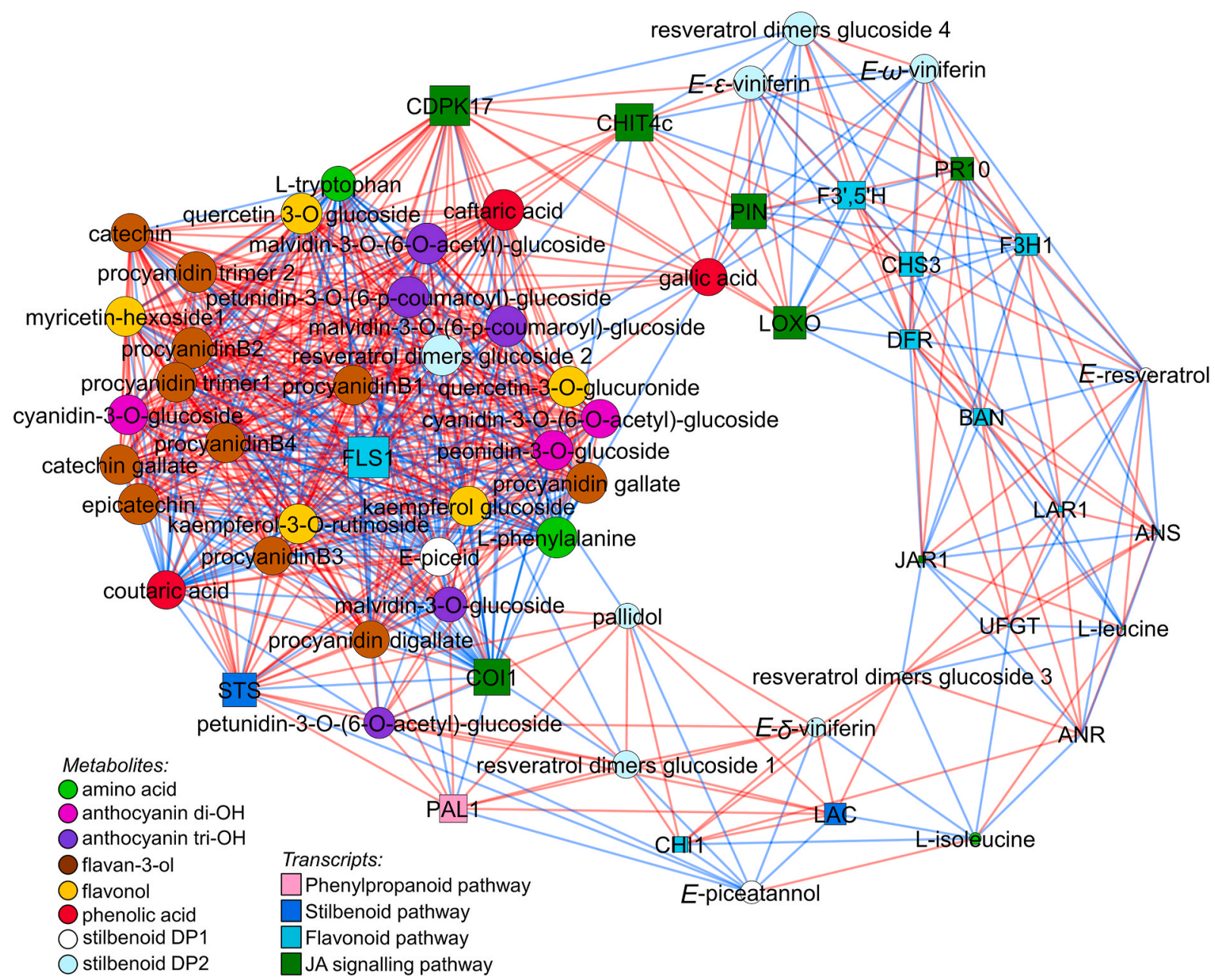

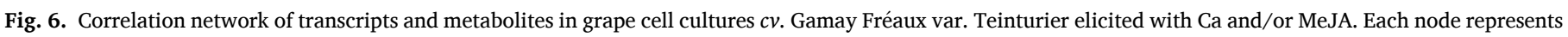

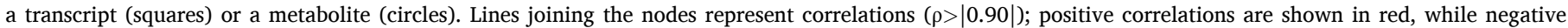

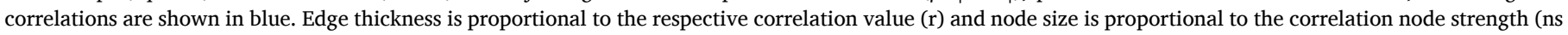

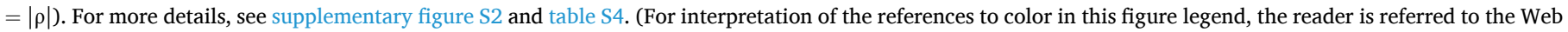
version of this article.) 
$F 3^{\prime}, 5^{\prime} H, C H S 3, F 3 H 1, D F R$, gallic acid, $E$ - $\omega$-viniferin, $E$ - $\varepsilon$-viniferin and resveratrol dimers glucoside 4. CHIT4c, PIN and LOXO establish a bridge between the first and second clusters, together with gallic acid, positively correlating with each other and with CDPK17. The first two transcripts negatively correlate with FLS1. E- $\omega$-viniferin and E- $\varepsilon$-viniferin exhibit opposite metabolite-metabolite and transcript-metabolite correlation patterns, negatively correlating with each other. PR10, LOXO, PIN and CHS3 positively correlate with each other, but correlate negatively with $F 3^{\prime}, 5^{\prime} H, F 3 H 1$ and $D F R$.

Connecting the second and third clusters is E-resveratrol which establishes only two metabolite-metabolite correlations, one negative with $E$ - $\omega$-viniferin and one positive with L-leucine from the third cluster. In addition, it correlates negatively with seven transcripts of the flavonoid pathway, excluding CHS3, but positively with the JA signaling transcripts JAR1 and PR1O (Fig. 6). The third cluster is thus composed of JAR1, LAR1, ANS, ANR, UFGT, LAC, E- $\delta$-viniferin, piceatannol, resveratrol dimers glucoside 3 and L-leucine (Fig. 6, supplementary figure S2). All flavonoid pathway transcripts establish positive transcript-transcript correlations, but negatively correlate with $J A R 1$ which positively correlates with $P R 10$. In addition, $L A C$ positively correlates with $E$ - $\delta$-viniferin and resveratrol dimers glucoside 3 but has a negative correlation with E-piceatannol.

The fourth cluster comprises PAL1, CHI1, pallidol and resveratrol dimers glucoside 1 (supplementary figure S2), all positively correlated with each other and with $L A C$ and $E$ - $\delta$-viniferin from the third cluster. $P A L 1$ plays a central connecting role between the fourth and first clusters, positively correlating with STS and negatively correlating with COI1 (Fig. 6).

\section{Discussion}

In the context of a wide project focused on the effect of exogenous $\mathrm{Ca}$ on grape berry physiology, we have previously demonstrated that it increases fruit firmness by modulating the expression of cell-wall genes (Martins et al., 2020b), deflects secondary metabolism towards the production of more stilbenoids and less anthocyanins in fruits and in cell cultures (Martins et al., 2020a), and counteracts the stimulatory effect of MeJA over several enzymes of secondary metabolism, among which PAL and UFGT (Martins et al., 2018). Also, a clear decrease in pigmentation was observed in grape cell cultures upon Ca treatment, both in comparison to control cells and to cells treated with MeJA. The main novelty of the present work thus relied on the establishment of a clear-cut relationship between $\mathrm{Ca}$ and MeJA in regulating polyphenolic metabolism routes in these pigmented grape cells through a targeted metabolomics approach coupled to directed gene expression studies, unravelling their joint regulatory network. Results showed that unlike $\mathrm{Ca}, \mathrm{MeJA}$ stimulated the production of both flavonoids and stilbenoids, more prominently DP2 stilbenoids. The stimulatory effect of MeJA over stilbenoid levels is in accordance to previous studies conducted in berries and cell cultures, where accumulation of E-resveratrol, $E$ - $\varepsilon$-viniferin and $E$-piceid was observed (Larronde et al., 2003; Tassoni et al., 2005; Vezzulli et al., 2007; Taurino et al., 2015). When the elicitors were combined, the stimulatory effect of MeJA over flavonoid synthesis was counterbalanced by the inhibitory effect of Ca. In parallel, a synergistic effect was observed specifically in the accumulation of $E$-resveratrol and $E$ - $\varepsilon$-viniferin. This result is particularly relevant in a biotechnological perspective, as cell cultures have increasingly been used in bioreactors for the production of resveratrol (Donnez et al., 2011; Jeandet et al., 2014; Nivelle et al., 2017; Chastang et al., 2018; Lambert et al., 2019). The release of resveratrol to the culture medium is significantly increased after cells elicitation with MeJA alone or in combination with cyclodextrin, chitosan or Na-orthovanadate (Tassoni et al., 2005; Belchí-Navarro et al., 2012). It would be noteworthy to further assess the effect $\mathrm{Ca}$ in these experimental conditions. Results of the present study further support the potential of $\mathrm{Ca}+\mathrm{MeJA}$ combination as a powerful approach for diverting polyphenolic metabolism towards the production of specific metabolites of interest, like $E$ - $\varepsilon$-viniferin.

As referred to above, the majority of flavonoids was significantly stimulated upon MeJA treatment in this study, in line with previous reports (Ruiz-García et al., 2012; García-Pastor et al., 2019). In parallel, only specific metabolites decreased upon MeJA + Ca treatment, namely the flavonols kaempferol- and quercetin-glucosides, the flavan 3-ols catechin and catechin-gallate and all di-OH anthocyanins (cyanidin and peonidin conjugates), while in previous studies a consistent repression of the entire flavonoid pathway upon Ca treatment was observed (Martins et al., 2020a).

Gene expression results of this study and from previous reports (Martins et al., 2018) suggest that Ca alone does not negatively impact most enzymes of the flavonoid pathway at transcriptional level, with the exception of $F 3 H 1, F 3^{\prime}, 5^{\prime} H$ and $F L S 1$, but rather acts at protein activity level (Fig. 5; Martins et al., 2018). However, when applied in combination with MeJA, Ca blocked the stimulatory effect exerted by the former, resulting in a strong downregulation of gene expression that is consistent with the lower-degree of flavonoid accumulation observed in the present study. The stimulatory effect of MeJA over CHS3, CHI, DFR, LAR1, ANR, UFGT is in accordance to previous studies, which denoted a good correlation with flavonoid levels (Belhadj et al., 2008; D'Onofrio et al., 2009). In turn, STS and LAC expression patterns were in agreement with the generalized increase in stilbenoid levels. The downregulation of $L A C$ could contribute for minimizing the conversion of $E$-resveratrol and E-piceatannol to oxidative products (Tavares et al., 2013). Forty-eight putative STS gene sequences were identified in grapevine, with at least 33 encoding full-length STS proteins, and multiple transcription factors regulate their expression (Vannozzi et al., 2012, 2018). In this regard, in our qPCR experiments, primers were designed to amplify several STS family genes, providing a broader overview of the changes in this metabolic pathway (Martins et al., 2018, 2020a, 2020a). Noteworthy, results in the present study further suggest that post-translational regulatory mechanisms also influence the accumulation of each particular metabolite, thus uncovering the intricate transcriptional and post-translational pathways involved in the regulation of STS enzymes is pivotal to understand the molecular mechanisms underlying stilbenoid synthesis.

In addition to modifications in polyphenol profile, results suggested that amino acid content was modulated by Ca and MeJA, namely Lphenylalanine levels which specifically decreased upon MeJA + Ca treatment, while $\mathrm{Ca}$ alone promoted its accumulation (Martins et al., 2020a). L-phenylalanine is the first substrate that fuels the secondary metabolism and its conversion to trans-cinnamic acid is catalyzed by PAL (Teixeira et al., 2013). This enzyme is also specifically inhibited by the MeJA + Ca, at enzyme activity and gene expression level, while Ca or MeJA alone have a stimulatory effect (Martins et al., 2018). In contrast, the levels of L-tryptophan, L-proline and L-isoleucine appeared to be only modulated by Ca (Martins et al., 2020a) but not by MeJA (this study). Accordingly, L-tryptophan levels were not affected by MeJA in grape berries (Moro et al. (2020).

Besides the direct effects of Ca and MeJA on grape cell polyphenolic metabolism, the evident influence of Ca on genes involved in JA synthesis and signaling, observed in the present study, further raised the level of complexity of the regulatory mechanisms mediated by these two powerful elicitors. Results unequivocally showed that Ca not only mimicked the effect of MeJA on the expression of some genes involved in JA signaling in grape cells, but also potentiated the response of JAsensitive pathogen related genes; in particular, PR10 upregulation was solely achieved by the combined action of the elicitors. Thus, MeJA and Ca signaling pathways seemed to be tightly interlinked in grape cells, mediating a fine-tuned regulation of several molecular and biochemical routes. In line with these findings, previous studies showed that the influx of Ca is necessary for elicitor-induced jasmonic acid synthesis and secondary metabolite accumulation in plant cells, through the action of Ca channels and sensors like CDPKs (Wasternack and Hause, 2002; Hu 
et al., 2009; Wang et al., 2019). A requirement of Ca influx has been reported for MeJA-induced grapevine defense responses (Faurie et al., 2009). In turn, JAs were shown to induce apoplastic Ca influx in Arabidopsis epidermal cells, increasing cytosolic free-Ca concentration; also, JA-induced gene expression could be triggered by higher concentration of extracellular Ca (Sun et al., 2006; Hu et al., 2009; Lu et al., 2016). In line with these findings, a network analysis performed in the present study using the transcriptional and metabolic data of cells elicited with $\mathrm{Ca}$ and/or MeJA exposed specific links between JA signaling and secondary metabolism. COI1 and CDPK17 occupied a core position in the main cluster, together with FLS1 and STS, suggesting their preponderant influence in the regulation of polyphenolic biosynthetic routes. Accordingly, previous studies showed that CDPKs and calmodulin modulate anthocyanin biosynthetic genes in Arabidopsis, strawberry and Vitis (Vitrac et al., 2000; Peng et al., 2016; Zou et al., 2017), besides regulating stilbenoid biosynthesis in Vitis (Aleynova et al., 2015). The involvement of COI1 in JA-activated anthocyanin accumulation has also been demonstrated in Arabidopsis (Qi et al., 2011), besides its close association with PAL-mediated secondary metabolic networks (Devoto et al., 2005), as observed in the present study. The involvement of COI1 in JA-induced transcription of CHS and DFR was also reported in Arabidopsis (Devoto et al., 2005; Wang et al., 2008), although no transcript-transcript correlations were observed in the present study. Our results further suggest that the metabolic steps involved in the synthesis of the different classes of flavonoids may share common regulatory mechanisms, as all metabolites within this pathway clustered closely together, exhibiting positive metabolite-metabolite correlations and very consistent transcript-metabolite correlations with FLS1, STS, CDPK17 and COI1. The multiple positive transcript-transcript correlations established in the flavonoid pathway also support this hypothesis. In contrast, stilbenoids appeared sparsely distributed along the 4 subnetworks, establishing specific correlations with 17 transcripts of multiple pathways, supporting a greater diversity in the regulation of stilbenoid biosynthetic pathways, as implied previously. Further studies are required to address this hypothesis. Specific transcript-transcript correlations among the JA pathway and the secondary metabolism pathways further support the concept of a strong interdependent regulatory network commanded by Ca and MeJA.

Many regulatory pathways described in this study can likely happen in planta, as consistent effects of isolated Ca and MeJA treatments on grape metabolism were observed in both cell cultures and in grape berries (Vezzulli et al., 2007; Belhadj et al., 2008; Martins et al., 2020a). The specific overaccumulation of $E$-resveratrol and $E$ - $\varepsilon$-viniferin upon MeJA + Ca treatment is particularly relevant for grape berry quality, as these phytoalexins were shown to be involved in MeJA-induced resistance to Botrytis cinerea (Wang et al., 2015). The stimulation of antioxidant activity and of pathogen-response genes triggered by Ca and MeJA (Jiang et al., 2015; Wang et al., 2015; Martins et al., 2021) further supports that the exogenous application of combined MeJA + Ca in grapevines can be envisaged as a promising eco-friendly strategy to improve grape berry tolerance to biotic stress.

\section{Conclusions}

Results in the present study showed that MeJA and Ca interact in the regulation of polyphenolic metabolism and adjacent JA signaling pathways. The combination of the elicitors favored the accumulation of specific stilbenoids like $E$-resveratrol and $E$ - $\varepsilon$-viniferin, while modulating the transcript levels of STS and LAC, showing a fine-tuned control of the stilbenoid pathway which could be relevant from a biotechnological perspective. The decreased flavonoid accumulation observed in cells treated with MeJA + Ca in comparison to cells treated with MeJA only is in line with the downregulation of genes of the flavonoid pathway, including LAR1, ANS, BAN and ANR. Results further showed that Ca could mimic or potentiate the effect of MeJA on the expression of JA signaling genes. Network analysis highlighted the joint central role of
FLS1, STS, CDPK17 and COI1 in the regulation of polyphenolic metabolism driven by $\mathrm{Ca}$ and/or MeJA, especially the flavonoid pathway, besides suggesting greater complexity in the regulation of the stilbenoid pathway.

\section{Funding}

This work was supported by the "Contrato-Programa" UIDB/04050/ 2020 funded by portuguese national funds through the FCT I.P. The work was also supported by FCT, CCDR-N (Norte Portugal Regional Coordination and Development Commission) and European Funds (FEDER/POCI/COMPETE2020) through the project AgriFood XXI (NORTE-01-0145-FEDER-000041) and the research projects BerryPlastid (PTDC/BIA-FBT/28165/2017 and POCI-01-0145-FEDER-028165) and MitiVineDrought (PTDC/BIA-FBT/30341/2017 and POCI-01-0145FEDER-030341). A.T. was supported by a postdoctoral researcher contract/position within the project "BerryPlastid". This article/publication is based upon work from COST Action CA 17111 INTEGRAPE, supported by COST (European Cooperation in Science and Technology) - in the context of a STSM to V.M. The Région-Centre Val de Loire (France) supported this work under the grant agreement to Projects CEPATLAS and VINODRONE to A.L.

\section{Authors contributions}

VM and HG conceptualized the work. VM performed cell elicitation experiments, sample processing and gene expression analyses. AL and MU performed metabolomic analysis and data treatment. AT performed network analysis. VM and HG wrote the manuscript. AL, AT, MU, VM and HG reviewed the manuscript. All authors contributed to the article and approved the submitted version.

\section{Declaration of competing interest}

The authors declare that they have no known competing financial interests or personal relationships that could have appeared to influence the work reported in this paper.

\section{Appendix A. Supplementary data}

Supplementary data to this article can be found online at https://doi. org/10.1016/j.plaphy.2021.05.034.

\section{References}

Aleynova, O.A., Dubrovina, A.S., Manyakhin, A.Y., Karetin, Y.A., Kiselev, K.V., 2015. Regulation of resveratrol production in Vitis amurensis cell cultures by calciumdependent protein kinases. Appl. Biochem. Biotechnol. 175 (3), 1460-1476.

Al-Qurashi, A.D., Awad, M.A., 2013. Effect of pre-harvest calcium chloride and ethanol spray on quality of 'El-Bayadi' table grapes during storage. Vitis 52 (2), 61-67.

Antunes, M.D.C., Panagopoulos, T., Rodrigues, S., Neves, N., Curado, F., 2004. June). The effect of pre-and postharvest calcium applications on Hayward kiwifruit storage ability. In: V International Postharvest Symposium, vol. 682, pp. 909-916.

Belchí-Navarro, S., Almagro, L., Lijavetzky, D., Bru, R., Pedreño, M.A., 2012. Enhanced extracellular production of trans-resveratrol in Vitis vinifera suspension cultured cells by using cyclodextrins and methyljasmonate. Plant Cell Rep. 31 (1), 81-89.

Belhadj, A., Telef, N., Saigne, C., Cluzet, S., Barrieu, F., Hamdi, S., Mérillon, J.M., 2008. Effect of methyl jasmonate in combination with carbohydrates on gene expression of PR proteins, stilbene and anthocyanin accumulation in grapevine cell cultures. Plant Physiol. Biochem. 46 (4), 493-499.

Billet, K., Delanoue, G., Arnault, I., Besseau, S., Oudin, A., Courdavault, V., et al., 2018a. Vineyard evaluation of stilbenoid-rich grape cane extracts against downy mildew: a large-scale study. Pest Manag. Sci. 75 (5), 1252-1257.

Billet, K., Houillé, B., Besseau, S., Mélin, C., Oudin, A., Papon, N., et al., 2018b. Mechanical stress rapidly induces E-resveratrol and E-piceatannol biosynthesis in grape canes stored as a freshly-pruned byproduct. Food Chem. 240, 1022-1027.

Billet, K., Houillé, B., de Bernonville, T.D., Besseau, S., Oudin, A., Courdavault, V., et al., 2018c. Field-based metabolomics of Vitis vinifera L. stems provides new insights for genotype discrimination and polyphenol metabolism structuring. Front. Plant Sci. 9.

Bogs, J., Downey, M.O., Harvey, J.S., Ashton, A.R., Tanner, G.J., Robinson, S.P., 2005. Proanthocyanidin synthesis and expression of genes encoding leucoanthocyanidin 
reductase and anthocyanidin reductase in developing grape berries and grapevine leaves. Plant Physiol. 139 (2), 652-663.

Bonomelli, C., Ruiz, R., 2010. Effects of foliar and soil calcium application on yield and quality of table grape cv. 'Thompson Seedless'. J. Plant Nutr. 33 (3), 299-314.

Castellarin, S.D., Pfeiffer, A., Sivilotti, P., Degan, M., Peterlunger, E., Di Gaspero, G., 2007. Transcriptional regulation of anthocyanin biosynthesis in ripening fruits of grapevine under seasonal water deficit. Plant Cell Environ. 30 (11), 1381-1399.

Chastang, T., Pozzobon, V., Taidi, B., Courot, E., Clément, C., Pareau, D., 2018. Resveratrol production by grapevine cells in fed-batch bioreactor: experiments and modelling. Biochem. Eng. J. 131, 9-16.

Chen, F., Fasoli, M., Tornielli, G.B., Dal Santo, S., Pezzotti, M., Zhang, L., et al., 2013. The evolutionary history and diverse physiological roles of the grapevine calciumdependent protein kinase gene family. PloS One 8 (12), e80818.

Ciccarese, A., Stellacci, A.M., Gentilesco, G., Rubino, P., 2013. Effectiveness of pre-and post-veraison calcium applications to control decay and maintain table grape fruit quality during storage. Postharvest Biol. Technol. 75, 135-141.

Cline, M.S., Smoot, M., Cerami, E., Kuchinsky, A., Landys, N., Workman, C., et al., 2007. Integration of biological networks and gene expression data using Cytoscape. Nat. Protoc. 2 (10), 2366.

Decendit, A., Merillon, J.M., 1996. Condensed tannin and anthocyanin production in Vitis vinifera cell suspension cultures. Plant Cell Rep. 15 (10), 762-765.

Demidchik, V., Shabala, S., Isayenkov, S., Cuin, T.A., Pottosin, I., 2018. Calcium transport across plant membranes: mechanisms and functions. New Phytol. 220 (1), 49-69.

Devoto, A., Ellis, C., Magusin, A., Chang, H.S., Chilcott, C., Zhu, T., Turner, J.G., 2005 Expression profiling reveals COI1 to be a key regulator of genes involved in woundand methyl jasmonate-induced secondary metabolism, defence, and hormone interactions. Plant Mol. Biol. 58 (4), 497-513.

Donnez, D., Kim, K.H., Antoine, S., Conreux, A., De Luca, V., Jeandet, P., et al., 2011. Bioproduction of resveratrol and viniferins by an elicited grapevine cell culture in a 2 L stirred bioreactor. Process Biochem. 46 (5), 1056-1062.

D'Onofrio, C., Cox, A., Davies, C., Boss, P.K., 2009. Induction of secondary metabolism in grape cell cultures by jasmonates. Funct. Plant Biol. 36 (4), 323-338.

Evans, J.D., 1996. Straightforward Statistics for the Behavioral Sciences. Thomson Brooks/Cole Publishing Co.

Faurie, B., Cluzet, S., Mérillon, J.M., 2009. Implication of signaling pathways involving calcium, phosphorylation and active oxygen species in methyl jasmonate-induced defense responses in grapevine cell cultures. J. Plant Physiol. 166 (17), 1863-1877.

Figueiredo, A., Monteiro, F., Sebastiana, M., 2015. First clues on a jasmonic acid role in grapevine resistance against the biotrophic fungus Plasmopara viticola. Eur. J. Plant Pathol. 142 (3), 645-652.

Gagné, S., Cluzet, S., Mérillon, J.M., Gény, L., 2011. ABA initiates anthocyanin production in grape cell cultures. J. Plant Growth Regul. 30 (1), 1-10.

García-Pastor, M.E., Serrano, M., Guillén, F., Castillo, S., Martínez-Romero, D., Valero, D., Zapata, P.J., 2019. Methyl jasmonate effects on table grape ripening, vine yield, berry quality and bioactive compounds depend on applied concentration. Sci. Hortic. 247, 380-389.

Hocking, B., Tyerman, S.D., Burton, R.A., Gilliham, M., 2016. Fruit calcium: transport and physiology. Front. Plant Sci. 7, 569.

Hu, X., Wansha, L., Chen, Q., Yang, Y., 2009. Early signals transduction linking the synthesis of jasmonic acid in plant. Plant Signal. Behav. 4 (8), 696-697.

Jeandet, P., Clément, C., Courot, E., 2014. Resveratrol production at large scale using plant cell suspensions. Eng. Life Sci. 14 (6), 622-632.

Jeong, S.T., Goto-Yamamoto, N., Kobayashi, S., Esaka, M.J.P.S., 2004. Effects of plant hormones and shading on the accumulation of anthocyanins and the expression of anthocyanin biosynthetic genes in grape berry skins. Plant Sci. 167 (2), 247-252.

Jiang, L., Jin, P., Wang, L., Yu, X., Wang, H., Zheng, Y., 2015. Methyl jasmonate primes defense responses against Botrytis cinerea and reduces disease development in harvested table grapes. Sci. Hortic. 192, 218-223.

Ju, Y.L., Liu, M., Zhao, H., Meng, J.F., Fang, Y.L., 2016. Effect of exogenous abscisic acid and methyl jasmonate on anthocyanin composition, fatty acids, and volatile compounds of Cabernet Sauvignon (Vitis vinifera L.) grape berries. Molecules 21 (10), 1354 .

Lambert, C., Lemaire, J., Auger, H., Guilleret, A., Reynaud, R., Clément, C., et al., 2019 Optimize, modulate, and scale-up resveratrol and resveratrol dimers bioproduction in Vitis labrusca L. cell suspension from flasks to $20 \mathrm{~L}$ bioreactor. Plants 8 (12), 567.

Larronde, F., Gaudillère, J.P., Krisa, S., Decendit, A., Deffieux, G., Mérillon, J.M., 2003. Airborne methyl jasmonate induces stilbene accumulation in leaves and berries of grapevine plants. Am. J. Enol. Vitic. 54 (1), 63-66.

Lu, M., Zhang, Y., Tang, S., Pan, J., Yu, Y., Han, J., et al., 2016. AtCNGC2 is involved in jasmonic acid-induced calcium mobilization. J. Exp. Bot. 67 (3), 809-819.

Madani, B., Mirshekari, A., Yahia, E., 2016. Effect of calcium chloride treatments on calcium content, anthracnose severity and antioxidant activity in papaya fruit during ambient storage. J. Sci. Food Agric. 96 (9), 2963-2968.

Martins, V., Billet, K., Garcia, A., Lanoue, A., Gerós, H., 2020a. Exogenous calcium deflects grape berry metabolism towards the production of more stilbenoids and less anthocyanins. Food Chem. 313, 126123.

Martins, V., Garcia, A., Alhinho, A.T., Costa, P., Lanceros-Méndez, S., Costa, M.M.R., Gerós, H., 2020b. Vineyard calcium sprays induce changes in grape berry skin, firmness, cell wall composition and expression of cell wall-related genes. Plant Physiol. Biochem. 150, 49-55.

Martins, V., Garcia, A., Costa, C., Sottomayor, M., Gerós, H., 2018. Calcium-and hormone-driven regulation of secondary metabolism and cell wall enzymes in grape berry cells. J. Plant Physiol. 231, 57-67.
Martins, V., Soares, C., Spormann, S., Fidalgo, F., Gerós, H., 2021. Vineyard calcium sprays reduce the damage of postharvest grape berries by stimulating enzymatic antioxidant activity and pathogen defense genes, despite inhibiting phenolic synthesis. Plant Physiol. Biochem. 162, 48-55.

Moro, L., Da Ros, A., da Mota, R.V., Purgatto, E., Mattivi, F., Arapitsas, P., 2020. LC-MS untargeted approach showed that methyl jasmonate application on Vitis labrusca L. grapes increases phenolics at subtropical Brazilian regions. Metabolomics 16 (2), $1-12$.

Nivelle, L., Hubert, J., Courot, E., Jeandet, P., Aziz, A., Nuzillard, J.M., et al., 2017. Anticancer activity of resveratrol and derivatives produced by grapevine cell suspensions in a $14 \mathrm{~L}$ stirred bioreactor. Molecules 22 (3), 474.

Peng, H., Yang, T., Whitaker, B.D., Shangguan, L., Fang, J., 2016. Calcium/calmodulin alleviates substrate inhibition in a strawberry UDP-glucosyltransferase involved in fruit anthocyanin biosynthesis. BMC Plant Biol. 16 (1), 197.

Qi, T., Song, S., Ren, Q., Wu, D., Huang, H., Chen, Y., et al., 2011. The jasmonate-ZIMdomain proteins interact with the WD-repeat/bHLH/MYB complexes to regulate jasmonate-mediated anthocyanin accumulation and trichome initiation in Arabidopsis thaliana. Plant Cell 23 (5), 1795-1814.

Reid, K.E., Olsson, N., Schlosser, J., Peng, F., Lund, S.T., 2006. An optimized grapevine RNA isolation procedure and statistical determination of reference genes for realtime RT-PCR during berry development. BMC Plant Biol. 6 (1), 27.

Ruiz-Garcia, Y., Romero-Cascales, I., Gil-Munoz, R., Fernandez-Fernandez, J.I., LopezRoca, J.M., Gomez-Plaza, E., 2012. Improving grape phenolic content and wine chromatic characteristics through the use of two different elicitors: methyl jasmonate versus benzothiadiazole. J. Agric. Food Chem. 60 (5), 1283-1290.

Siddiqui, S., Bangerth, F., 1995. Effect of pre-harvest application of calcium on flesh firmness and cell-wall composition of apples-influence of fruit size. J. Hortic. Sci. 70 (2), 263-269.

Sun, Q.P., Guo, Y., Sun, Y., Sun, D.Y., Wang, X.J., 2006. Influx of extracellular $\mathrm{Ca}^{2+}$ involved in jasmonic-acid-induced elevation of $\left[\mathrm{Ca}^{2+}\right]$ cyt and JR1 expression in Arabidopsis thaliana. J. Plant Res. 119 (4), 343-350.

Taurino, M., Ingrosso, I., D'amico, L., De Domenico, S., Nicoletti, I., Corradini, D., et al., 2015. Jasmonates elicit different sets of stilbenes in Vitis vinifera cv. Negramaro Cell Cult. 4 (1), 1-11. Springer Plus.

Tassoni, A., Fornalè, S., Franceschetti, M., Musiani, F., Michael, A.J., Perry, B., Bagni, N., 2005. Jasmonates and Na-orthovanadate promote resveratrol production in Vitis vinifera cv. Barbera cell cultures. New Phytol. 166 (3), 895-905.

Tavares, S., Vesentini, D., Fernandes, J.C., Ferreira, R.B., Laureano, O., Ricardo-DaSilva, J.M., Amâncio, S., 2013. Vitis vinifera secondary metabolism as affected by sulfate depletion: diagnosis through phenylpropanoid pathway genes and metabolites. Plant Physiol. Biochem. 66, 118-126.

Teixeira, A., Eiras-Dias, J., Castellarin, S.D., Gerós, H., 2013. Berry phenolics of grapevine under challenging environments. Int. J. Mol. Sci. 14 (9), 18711-18739.

Teixeira, A., Martins, V., Frusciante, S., Cruz, T., Noronha, H., Diretto, G., Gerós, H., 2020. Flavescence dorée-derived leaf yellowing in grapevine (Vitis vinifera L.) is associated to a general repression of isoprenoid biosynthetic pathways. Front. Plant Sci. 11, 896 .

Vannozzi, A., Dry, I.B., Fasoli, M., Zenoni, S., Lucchin, M., 2012. Genome-wide analysis of the grapevine stilbene synthase multigenic family: genomic organization and expression profiles upon biotic and abiotic stresses. BMC Plant Biol. 12 (1), 130.

Vannozzi, A., Wong, D.C.J., Höll, J., Hmmam, I., Matus, J.T., Bogs, J., et al., 2018. Combinatorial regulation of stilbene synthase genes by WRKY and MYB transcription factors in grapevine (Vitis vinifera L.). Plant Cell Physiol. 59 (5), 1043-1059.

Vezzulli, S., Civardi, S., Ferrari, F., Bavaresco, L., 2007. Methyl jasmonate treatment as a trigger of resveratrol synthesis in cultivated grapevine. Am. J. Enol. Vitic. 58 (4), 530-533.

Vitrac, X., Larronde, F., Krisa, S., Decendit, A., Deffieux, G., Mérillon, J.M., 2000. Sugar sensing and $\mathrm{Ca}^{2+}$-calmodulin requirement in Vitis vinifera cells producing anthocyanins. Phytochemistry 53 (6), 659-665.

Wang, Z., Cao, G., Wang, X., Miao, J., Liu, X., Chen, Z., et al., 2008. Identification and characterization of COI1-dependent transcription factor genes involved in JAmediated response to wounding in Arabidopsis plants. Plant Cell Rep. 27 (1), $125-135$.

Wang, K., Liao, Y., Kan, J., Han, L., Zheng, Y., 2015. Response of direct or priming defense against Botrytis cinerea to methyl jasmonate treatment at different concentrations in grape berries. Int. J. Food Microbiol. 194, 32-39.

Wang, X., Zhu, B., Jiang, Z., Wang, S., 2019. Calcium-mediation of jasmonate biosynthesis and signaling in plants. Plant Sci. 287, 110192

Wasternack, C., Hause, B., 2002. Jasmonates and octadecanoids: signals in plant stress responses and development. Prog. Nucleic Acid Res. Mol. Biol. 72, 165-221.

Wójcik, P., Borowik, M., 2013. Influence of preharvest sprays of a mixture of calcium formate, calcium acetate, calcium chloride and calcium nitrate on quality and 'Jonagold' apple storability. J. Plant Nutr. 36 (13), 2023-2034.

Wójcik, P., Lewandowski, M., 2003. Effect of calcium and boron sprays on yield and quality of "Elsanta" strawberry. J. Plant Nutr. 26 (3), 671-682.

Yu, J., Zhu, M., Wang, M., Xu, Y., Chen, W., Yang, G., 2020. Transcriptome analysis of calcium-induced accumulation of anthocyanins in grape skin. Sci. Hortic. 260, 108871.

Zou, B., Wan, D., Li, R., Han, X., Li, G., Wang, R., 2017. Calmodulin-binding protein CBP60g functions as a negative regulator in Arabidopsis anthocyanin accumulation. Plos One 12 (3), e0173129. 